\title{
A Case Report: Primary Melanoma of the Nasal Cavity
}

\author{
S Belli ${ }^{1}$, S Yalcin ${ }^{2}$, MF Oktay ${ }^{1}$
}

\begin{abstract}
We report a rare case of sinonasal mucosal malignant melanoma in the nasal cavity. The patient had respiratory difficulty, continuous epistaxis and nasal pain. We identified a malignant tumour which is a rare pathology with detailed physical examination, anterior rhinoscopy, computed tomography (CT) scan, magnetic resonance imaging (MRI) and histopathologic examination. The patient did not accept surgical procedures and was referred for chemotherapy or immunotherapy. Continued follow-up of this is necessary.
\end{abstract}

Keywords: Anterior rhinoscopy, computed tomography scan, histopathologic examination, magnetic resonance imaging, malignant melanoma, nasal cavity

\section{Un Reporte de Caso: Melanoma Primario de la Cavidad Nasal S Belli ${ }^{1}$, S Yalcin $^{2}$, MF Oktay ${ }^{1}$}

\section{RESUMEN}

Reportamos un caso raro de melanoma maligno de la mucosa del tracto nasosinusal. El paciente tenía dificultad respiratoria, epistaxis continua, y dolor nasal. Identificamos un tumor maligno que es una patología, con examen fisico detallado, rinoscopia anterior, tomografía computarizada (TC), resonancia magnética (MRI) y examen histopatológico. El paciente no aceptaba los procedimientos quirúrgicos y fue remitido para quimioterapia o inmunoterapia. Es necesario realizar un seguimiento continuo.

Palabras claves: Rinoscopia anterior, tomografía computarizada, examen histopatológico, resonancia magnética, melanoma maligno, cavidad nasal

West Indian Med J 2013; 62 (8): 778

\section{INTRODUCTION}

Cancers of the nasal cavity and perinasal sinuses occur in approximately $0.2 \%$ to $0.5 \%$ of malignant tumours in general. Histology is commonly squamous cell carcinoma. Malignant melanoma of the nasal cavity and perinasal sinuses constitutes less than $1 \%$ of the tumours of this location. On the other hand, the head and neck area accounts for approximately $20 \%$ of all (cutaneous and mucosal) melanomas. Only $1 \%$ arise in the sinonasal tract (1). The most common location sites are the septum and inferior turbinate. Primary melanoma of the nose ridge is extremely rare. In a reiew of 194 reported cases of sinonasal melanoma by Batsakis et al (2), none originated in the nose ridge. This tumour does not show preference by gender (1). The peak

From: ${ }^{1}$ Department of Otorhinolaryngology and ${ }^{2}$ Department of Pathology, Bagcilar Education and Research Hospital, Istanbul, Turkey.

Correspondence: Dr S Belli, Bağcilar Eğitim ve Araştirma Hastanesi, Bağcilar, Istanbul, Turkey. Fax: +90 21244040 02, e-mail: drseydabelli@ gmail.com incidence occurs in patients in their fifth to eighth decades of life (3). Epistaxis and nasal obstruction are the most common presenting symptoms of sinonasal tract melanomas. The lesion usually appears as a polypoid fleshy mass on physical examination and may be solitary or multicentric (4). Intranasal malignant melanoma can be bleeding or not, pigmented or white (1). Nasal malignant melanoma is a rare and aggressive cancer with a very poor outcome.

We report herein a rare case of sinonasal mucosal malignant melanoma in the nasal cavity.

\section{CASE REPORT}

An 73-year old woman had a 1.5-month history of respiratory difficulty, continuous epistaxis and nasal pain. The examination with anterior rhinoscopy revealed a left intranasal polypoid tumour of $2 \mathrm{~cm}$, pigmented and bleeding when manipulated. Endoscopic office nasal examination revealed a fleshy, friable mass in the left nasal dorsum (Fig. 1).

Computed tomography (CT) scan revealed an increased density compatible with soft tissue in the left median 


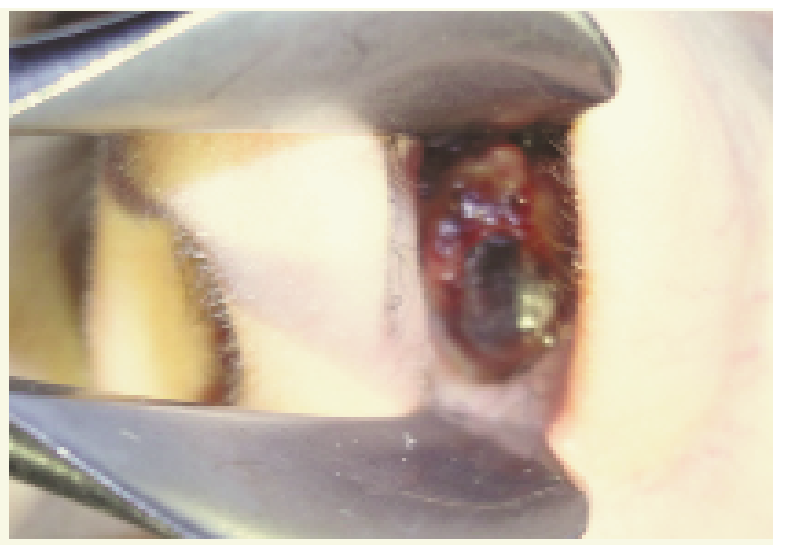

Fig. 1: Preoperative endoscopic image of the mass in the left naris.

anterior portion of the nasal cavity in the coronal and axial plane of the paranasal sinus. The patient underwent magnetic resonance imaging (MRI) that showed a solid lesion in the left anterior naris which was located adjacent to the anterolateral wall of the nasal septum. Magnetic resonance imaging examination showed a hypodense mass $23.4 \times 16.7 \mathrm{~mm}$ in size with contrast enhancement after gadolinium administration (Fig. 2).

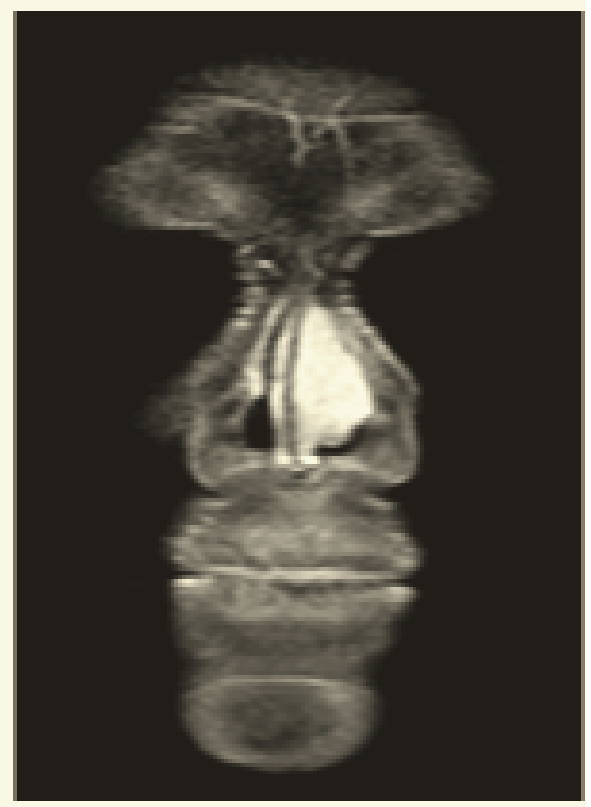

Fig. 2: Magnetic resonance image of the mass after gadolinium administration.

An endoscopic intranasal biopsy of the mass was performed in the office with the patient under local anaesthesia. On histopathologic examination, the tumour was found to be composed of sheets of dyshesive malignant epithelioid cells. When microscopic sections were stained with haematoxylin and eosin, prominent eosinophilic nucleoli in epithelial cells with irregular contours and vesicular nuclei, located in the tumoural infiltration of spindle-shaped cells, were observed (Fig. 3). Immunohistochemical stain on formalin-fixed,

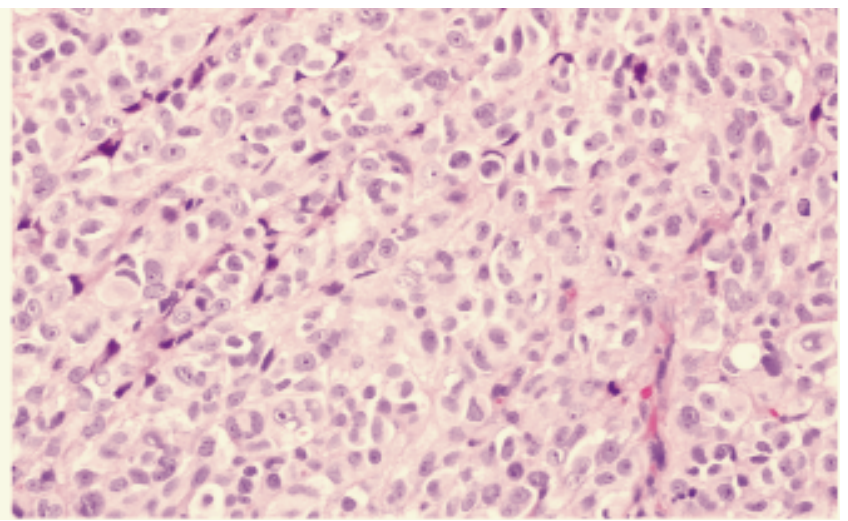

Fig. 3: Microscopic sections of the tumour cells dyed with haematoxylin and eosin revealed infiltration of cells with spindle shaped edges.

paraffin-embedded tissue showed tumour cells which stained for S100 protein and HMB45 antigen but not for keratin or leukocyte common antigen, supporting the diagnosis of melanoma.

The patient gave no history of previously diagnosed cutaneous or mucosal melanomas at other sites. Further work-up, MRI studies of the chest and abdomen showed no evidence of distant metastasis or evidence of primary sites. According to these findings, the tumour was regarded as a well-identified malignant melanoma, a rare tumour of the nasal dorsum.

\section{DISCUSSION}

Sinonasal mucosal malignant melanomas are comparatively rare in the nasal cavity, and represent between 0.5 and $1.5 \%$ of all melanomas $(5,6)$ and $<5 \%$ of all sinonasal tract neoplasms (5). Malignant melanomas typically affect older individuals in the fifth to eigth decade of life with a peak incidence in the seventh decade. Formaldehyde exposure and tobacco smoking have been suggested as possible aetiologic factors (5). However, the index patient did not have these risk factors.

These tumours seem to originate from melanocytes present in the mucosa of the respiratory tract. Cardesa et al report that it is not uncommon to see melanomas arising in an area of squamous metaplasia (6). The aetiologic and pathogenic bases for the origin of mucosal malignant melanomas, however, are far less understood than those for cutaneous melanomas (3). Although there is not a significant gender predilection, a report has been described where men seem to be affected more than women (6).

The nasal cavity is affected most frequently, followed by a combination of the nasal cavity and paranasal sinuses ( 3 , 5). The most common location sites are the septum, anterior nasal portion and inferior turbinate $(1,6)$. The mass was observed in the dorsum of the nasal cavity in this case.

The signs and symptoms of presentation of sinonasal malignant melanomas are not specific. Epistaxis and nasal obstruction are frequent when located in the nasal cavity. 
The lesion usually appears as a polypoid fleshy mass on physical examination and may be solitary or multicentric (3, 6 ). The tumour also showed a polypoid fleshy mass in our case.

The mainstay of treatment for mucosal malignant melanoma is surgical resection. For intranasal cases, the largest adequate operation is usually the best for local control. Elective neck dissection is not advocated. Postoperative radiation therapy may be beneficial, although its impact on survival and local control has not been adequataly documented. The role of chemotherapy or immunotherapy has not been well studied (3). However, we were not able to perform surgical oncological procedure on the index case. The patient was referred for chemotherapy or immunotherapy and will be followed up.

Five-year survival of sinonasal malignant melanoma is reportedly under $35 \%$. Patients with primary nasal malignant melanomas had a significantly better five-year survival rate than patients with melanomas from other head and neck sites (6).

In summary, a case of sinonasal mucosal malignant melanoma was diagnosed in the nasal cavity. The patient had respiratory difficulty, continuous epistaxis and nasal pain.

\section{REFERENCES}

1. Mercado-Rey M. Intranasal malignant melanoma. Otolaryngol Head Neck Surg 2007; 137 (Suppl 2): 202.

2. Batsakis JG, Regezi JA, Solomon AR, Rice DH. The pathology of head and neck tumors: mucosal melanomas, part 13. Head Neck Surg 1982; 4: 404-18.

3. Busaba NY. Primary melanoma of the sphenoid sinus. Otolaryngol Head Neck Surg 2000; 123: 748-9.

4. Holdcraft J, Gallagher JC. Malignant melanomas of the nasal and paranasal sinus Mucosa. Ann Otol Rhinol Laryngol 1969; 78: 5-20.

5. Barnes L, Eveson JW, Reichart P, Sidransky D, eds. World Health Organisation classification of tumours. Pathology and genetics of head and neck tumours. Lyon: IARC Press; 2005: 72-4.

6. Cardesa A, Slootweg PJ. Pathology of the Head and Neck. Berlin: Springer; 2006: 55-7. 